\title{
Correction to: Cross-border comparison of antimicrobial resistance (AMR) and AMR prevention measures: the healthcare workers' perspective
}

J. Keizer ${ }^{1 *}$, L. M. A. Braakman-Jansen', S. Kampmeier ${ }^{2}$, R. Köck ${ }^{2,3,4}$, N. Al Naiemi ${ }^{5,6}$, R. Te Riet-Warning ${ }^{5}$, N. Beerlage-De Jong ${ }^{1}$, K. Becker $^{3}$ and J. E. W. C. Van Gemert-Pijnen ${ }^{1}$

\section{Correction to: Antimicrob Resist Infect Control} (2019) 8:123

https://doi.org/10.1186/s13756-019-0577-4

The original article [1] contained a minor editorial typo in the following sentence which has now been corrected:

'Social desirability bias might always have occurred, since most people are aware that AMR should require special attention (note that this does not mean that it gets special attention in daily working routines).'

\footnotetext{
Author details

'Department of Psychology, Health and Technology, Centre for eHealth and Wellbeing Research, University of Twente, P.O. Box 217, 7500AE Enschede, The Netherlands. ${ }^{2}$ Institute of Hygiene, University Hospital Münster, Münster, Germany. ${ }^{3}$ Institute of Medical Microbiology, University Hospital Münster, Münster, Germany. ${ }^{4}$ Institute of Hospital Hygiene Oldenburg, Oldenburg, Germany. ${ }^{5}$ Department of Infection Prevention, Hospital Group Twente, Almelo/Hengelo, Netherlands. 'LabMicTA, Hengelo, Netherlands.
}

Published online: 08 August 2019

\section{Reference}

1. Keizer J, Braakman-Jansen LMA, Kampmeier S, Köck R, Al Naiemi N, Te Riet-Warning $R$, et al. Cross-border comparison of antimicrobial resistance (AMR) and AMR prevention measures: the healthcare workers' perspective. Antimicrob Resist Infect Control. 2019;8:123. https://doi. org/10.1186/s13756-019-0577-4.

\footnotetext{
* Correspondence: j.keizer@utwente.nl

${ }^{1}$ Department of Psychology, Health and Technology, Centre for eHealth and Wellbeing Research, University of Twente, P.O. Box 217, 7500AE Enschede, The Netherlands

Full list of author information is available at the end of the article
}

(c) The Author(s). 2019 Open Access This article is distributed under the terms of the Creative Commons Attribution 4.0 International License (http://creativecommons.org/licenses/by/4.0/), which permits unrestricted use, distribution, and reproduction in any medium, provided you give appropriate credit to the original author(s) and the source, provide a link to the Creative Commons license, and indicate if changes were made. The Creative Commons Public Domain Dedication waiver (http://creativecommons.org/publicdomain/zero/1.0/) applies to the data made available in this article, unless otherwise stated. 